\title{
O jogo da compreensão na análise textual discursiva em pesquisas na educação em ciências: revisitando quebra-cabeças e mosaicos
}

\section{The understanding game in discursive textual analysis in Science Education researches: revisiting puzzles and mosaics}

\author{
Robson Simplicio de Sousa ${ }^{1}$ \\ http://orcid.org/0000-0002-4637-5014 \\ Maria do Carmo Galiazzi² \\ https://orcid.org/0000-0003-0513-0018
}

\begin{abstract}
Resumo: Analisaram-se dezesseis resumos de teses defendidas entre 2012 e 2017 em um Programa de Pós-Graduação em Educação em Ciências, que usaram a metodologia Análise Textual Discursiva (ATD) a partir da pergunta fenomenológica: "O que é isto que se mostra acerca da metodologia ATD nos resumos de teses em Educação em Ciências?” Partiu-se de um exercício fenomenológico, seguido de uma análise hermenêutica, com busca da etimologia das palavras para ampliar significados na linguagem. Como resultado, chegou-se às categorias: "O quebra-cabeças: a descrição e as teorias a priori como précompreensões" e "O mosaico: o movimento para compreensão". Compreendeu-se que fazer pesquisa com a ATD envolve procedimentos analíticos de cunho fenomenológico-hermenêutico que consistem na descrição do fenômeno percebido, seguida do movimento de análise na espiral hermenêutica. Buscouse, com isto, a fusão de horizontes sobre a temática, adensando a compreensão de que a ATD é uma metodologia cada vez mais inserida na hermenêutica gadameriana.
\end{abstract}

Palavras-chave: Análise textual discursiva. Teses. Educação em ciências. Hermenêutica. Fenomenologia.

\begin{abstract}
Sixteen thesis abstracts were analyzed that had been defended from 2012 to 2017 in a Postgraduate Program in Science Education, which used the Discursive Textual Analysis methodology (DTA). The phenomenological question posed was: "What is shown by the DTA methodology in the abstracts of doctoral theses in Science Education?” It was based on a phenomenological exercise, followed by a hermeneutical analysis, with searches for the etymology of words in pursuit of language meanings. As a result, the following categories were determined: "The puzzle: description and a priori theories as pre-understandings" and "The mosaic: the movement for understanding". It was understood that doing research with DTA involves phenomenological-hermeneutic analytical procedures that consist of the description of the perceived phenomenon, followed by the analysis movement in the hermeneutical spiral. With this, the fusion of horizons about the theme was sought, increasing the understanding that the ATD is a methodology increasingly inserted in Gadamerian hermeneutics.
\end{abstract}

Keywords: Discursive textual analysis. Thesis. Science education. Hermeneutics. Phenomenology.

\footnotetext{
${ }^{1}$ Universidade Federal do Triângulo Mineiro (UFTM), Iturama, MG, Brasil. E-mail: <robson.sousa@uftm.edu.br>. ${ }^{2}$ Universidade Federal do Rio Grande (FURG), Programa de Pós-Graduação em Educação em Ciências, Química da Vida e Saúde, Rio Grande, RS, Brasil.
} 


\section{Introdução}

A Análise Textual Discursiva (ATD) tem sido muito utilizada em programas de pósgraduação no Brasil, alcançando mais de mil e duzentas citações em trabalhos de pesquisa em língua portuguesa ${ }^{3}$ desde sua publicação há mais de uma década (MORAES; GALIAZZI, 2007). Originou-se do encontro com a fenomenologia de Husserl e de Merleau-Ponty com a pesquisa naturalística, com o existencialismo e com a hermenêutica existencial de Heidegger (MORAES, 1991). Anteriormente, a pesquisa quantitativa e a Análise de Conteúdo foram as abordagens mais presentes nas pesquisas de Roque Moraes. Ao atuar em cursos de pós-graduação, o modo de analisar as pesquisas sob sua orientação foi sendo deslocado. O trabalho iniciado na década de 1980 com Maurivan Guntzel Ramos e o encontro com Maria do Carmo Galiazzi, ambos seus orientados de doutorado, resultou na proposição da ATD (MORAES, 2003; MORAES; GALIAZZI, 2006; MORAES; GALIAZZI; RAMOS, 2013). A aplicação da ATD como metodologia de análise em monografias, dissertações e teses está bem presente, especialmente na Educação em Ciências, como uma ação metodológica para desprender-se do reducionismo epistêmico concretizado no esquematismo do sujeito-objeto (BERTICELLI, 2006), ainda presente nas Ciências Naturais.

Moraes e Galiazzi (2007) apresentam a ATD como uma metodologia de análise de informação de natureza qualitativa para produzir novas compreensões sobre textos e discursos. O livro está organizado em capítulos com pontos de abordagem do processo de análise como um todo, intercalados com capítulos que tratam das partes do processo. Em termos procedimentais, a ATD orienta a organização da análise em desmontagem dos textos, estabelecimento de relações e captando o novo emergente. Busca-se, com a ATD, o aprofundamento do pesquisador sobre o processo desconstrutivo chamado de unitarização, processo recursivo de mergulho nos sentidos atribuídos aos textos em análise. Das unidades de significado, encaminha-se para o processo de organização de unidades com a elaboração de categorias iniciais, que, aproximadas, possibilitam a elaboração de categorias intermediárias e, em um novo esforço perceptivo, emergem no horizonte de compreensão do pesquisador categorias finais acerca do fenômeno. A categorização se apresenta como processo de aprendizagem e comunicação de novos entendimentos em um movimento de síntese e construção de sistemas de categorias com as novas aprendizagens e compreensões que originam um metatexto (MORAES; GALIAZZI, 2007; SOUSA; GALIAZZI, 2017a).

Neste artigo, buscou-se compreender como se mostra a ATD desenvolvida em resumos de teses de doutorado. Pretendeu-se não saber o que os autores das teses quiseram dizer ou mesmo partir de uma teorização, enquadrando as diferentes pesquisas em procedimentos coerentes com o proposto pela metodologia. Entretanto, carregam-se pressupostos teóricos que fazem parte de nossas pre-compreensões durante a análise e que constituem o jogo analítico da própria ATD. A intenção foi, portanto, compreender o que dos resumos das pesquisas se mostrou na linguagem para que ocorresse a fusão de horizontes de compreensão dos pesquisadores das teses analisadas, dos autores deste texto e da própria ATD. Trata-se, portanto, de um

\footnotetext{
${ }^{3}$ Consulta realizada no Google Acadêmico em fevereiro de 2018.
} 
O jogo da compreensão na análise textual discursiva em pesquisas ...

exercício de percepção-interpretação do que os textos mostrados escolhidos como corpus de análise - resumos das teses que utilizaram a ATD - têm a dizer para os autores deste artigo no encontro com seus pressupostos do que reconstruir a situação original do texto ou estabelecer uma verdade definitiva.

Assim, partiu-se do modo de perguntar fenomenológico, interrogando O que é isso que se mostra da metodologia Análise Textual Discursiva nos resumos de teses de um programa de pós-graduação em Educação em Ciências? No total foram dezesseis resumos de teses defendidas de 2012 a 2017 no Programa de Pós-Graduação em Educação em Ciências (PPGEC) da Universidade Federal do Rio Grande (FURG) que utilizaram a ATD. Estes resumos foram o corpus de análise e organizados em uma Unidade Hermenêutica do software Atlas.ti, conforme já mostrado em Ariza et al. (2016). Os resumos das teses abrangeram as produções defendidas desde o início do Programa de Pós-graduação. Realizou-se a Análise Textual Discursiva desses resumos, em que se partiu da unitarização, seguida da categorização e elaboração de um metatexto em uma abordagem fenomenológica e hermenêutica. Mostrou-se como fenômeno situado: A Compreensão com a Análise Textual Discursiva. Emergiram deste fenômeno duas categorias abertas denominadas "O quebra-cabeças: a descrição e as teorias a priori como pré-compreensões" e "O mosaico: o movimento para compreensão".

\section{O jogo de compreender pela pesquisa: o fenômeno na Análise Textual Discursiva}

O fenômeno que se mostrou a partir da leitura e da análise dos resumos das teses foi a compreensão porque os objetivos explicitados em quinze dos dezesseis resumos analisados foram de alcançar a compreensão como evidenciado no Quadro 1. A análise possibilitou a construção da seguinte síntese descritiva: os resumos das teses mostraram que as investigações analisadas tiveram como objetivo a busca de compreensão com a Análise Textual Discursiva dos fenômenos relacionados ao ensino e à aprendizagem na Educação em Ciências. Isso remeteu a compreender pela Análise Textual Discursiva a compreensão em um jogo analítico fenomenológico-hermenêutico, iniciando com a descrição das unidades de significado do fenômeno situado em análise que levou ao exercício hermenêutico e produção de metatextos interpretativos.

Assim, a partir da leitura de todos os resumos, o que se mostrou como fenômeno de compreender ou a compreensão como modo de produzir conhecimento em Educação em Ciências. Questionou-se, assim, acerca do que vem a ser o compreender/ a compreensão.

Em um exercício descritivo de busca etimológica da palavra compreender, o vocábulo tem origem latina e foi encontrado em registros escritos de Língua Portuguesa a partir do século XIII (CUNHA, 1982). Compreender apresenta o prefixo com que significa junto, em associação, seguido da palavra prehendere que significa segurar, prender fortemente. A palavra latina comprehendo assumiu este significado de que o que se compreende é o que está dentro do compreendido; é o que consta dentro do que é compreendido, ao mesmo tempo em que inclui o sujeito que compreende ao significar que o compreendido é percebido e entendido. Os significados mantiveram a origem de conter em si, na sua natureza, numa categoria ou num sistema e também de apreender algo intelectualmente, usando a capacidade de entendimento, percepção, atino. Também, na cultura, compreender pode significar que a ação foi estendida, ou seja, do compreendido anterior algo foi incluído, incorporado. Também pode significar a 
concepção de um sujeito sobre determinada coisa. À palavra compreender se agregam significados como o espírito de complacência para com as dificuldades bem como de estabelecer o conjunto de características, qualidades propriedades contidas em um conceito e de comunicar com coerência a mensagem (HOUAISS; VILLAR, 2009). Em termos etimológicos e de acepções dicionarizadas, compreender está para além do domínio de um objeto, que inclui aquele que busca compreensão. É um compreender como ato de conhecer e conhecer-se, de conter em si, constar, abranger, perceber, entender e de significar o espírito de complacência com as dificuldades. Complacência essa como finitude daquele que (se) compreende, inclusive em relação a suas dificuldades e a dos outros envolvidos nesse processo de compreensão.

Quadro 1. A compreensão como intenção investigativa identificada nos resumo de teses que utilizaram a Análise Textual Discursiva como metodologia analítica no Programa de Pós-Graduação em Ciências: Química da Vida e Saúde (PPGEC) da Universidade Federal do Rio Grande (FURG) de 2012 a 2017

\begin{tabular}{|c|c|}
\hline Tese & Excerto \\
\hline $\begin{array}{l}\text { ALBUQUERQUE, F. M. D. Histórias de } \\
\text { sala de aula nas rodas de professores de } \\
\text { química: potência para a formação acadêmico- } \\
\text { profissional. } 2012.110 \text { f. Tese (Doutorado em } \\
\text { Educação em Ciências) - Universidade Federal } \\
\text { do Rio Grande, Rio Grande, } 2012 .\end{array}$ & $\begin{array}{l}\text { "A análise das histórias escritas pelos participantes } \\
\text { desta pesquisa, realizada mediante a Análise } \\
\text { Textual Discursiva possibilitou a compreensão da } \\
\text { contribuição das histórias na formação acadêmico- } \\
\text { profissional de licenciandos de Química da FURG } \\
\text { em Rodas de Formação.” (p. 5, grifo nosso). }\end{array}$ \\
\hline $\begin{array}{l}\text { ALVARENGA, A. M. A construção do } \\
\text { currículo interdisciplinar: da regeneração dos } \\
\text { princípios ao fortalecimento da formação dos } \\
\text { professores. 2016. } 123 \text { f. Tese (Doutorado em } \\
\text { Educação em Ciências) - Universidade Federal } \\
\text { do Rio Grande, Rio Grande, } 2016 .\end{array}$ & $\begin{array}{l}\text { "O objetivo geral desta tese foi investigar o } \\
\text { processo de organização curricular do curso } \\
\text { de Licenciatura em Ciências Exatas (LCE), da } \\
\text { Universidade Federal do Pampa (UNIPAMPA), } \\
\text { identificando e compreendendo os processos de } \\
\text { inovação curricular." (p. 7, grifo nosso). }\end{array}$ \\
\hline $\begin{array}{l}\text { ARAÚJO, R. R. Entre sonhos e realidades: } \\
\text { a auto-eco-formação interdisciplinar de } \\
\text { professores em ciências da natureza. 2017.155 } \\
\text { f. Tese (Doutorado em Educação em Ciências) } \\
\text { - Universidade Federal do Rio Grande, Rio } \\
\text { Grande, } 2017 .\end{array}$ & $\begin{array}{l}\text { "a pesquisa teve por objetivo geral investigar e } \\
\text { compreender como se constituem os lugares } \\
\text { e oportunidades de formação interdisciplinar } \\
\text { experienciadas por estudantes de um curso de } \\
\text { Licenciatura em Ciências da Natureza." (p. 9, grifo } \\
\text { nosso). }\end{array}$ \\
\hline $\begin{array}{l}\text { CACCIAMANI, J. L. M. Os Encontros sobre } \\
\text { investigação na escola: articulação entre a } \\
\text { formação acadêmico-profissional e a produção } \\
\text { de currículo pela escrita da sala de aula. } \\
\text { 2012. } 150 \text { f. Tese (Doutorado em Educação } \\
\text { em Ciências) - Universidade Federal do Rio } \\
\text { Grande, Rio Grande, 2012. }\end{array}$ & $\begin{array}{l}\text { "O presente trabalho de pesquisa de tese } \\
\text { de doutoramento procura compreender a } \\
\text { potencialidade dos Encontros sobre Investigação na } \\
\text { Escola na formação permanente dos professores de } \\
\text { Química." (p. 11, grifo nosso). }\end{array}$ \\
\hline $\begin{array}{l}\text { CRIVELLARO, C. V. L. Flores de energia: a } \\
\text { experiência do NEMA - Núcleo de Educação } \\
\text { e Monitoramento Ambiental na constituição } \\
\text { de intelectuais orgânicos. 2013. } 203 \text { f. Tese } \\
\text { (Doutorado em Educação em Ciências) - } \\
\text { Universidade Federal do Rio Grande, Rio } \\
\text { Grande, } 2013 .\end{array}$ & $\begin{array}{l}\text { "Este estudo visa compreender a experiência do } \\
\text { NEMA - Núcleo de Educação e Monitoramento } \\
\text { Ambiental na constituição de intelectuais } \\
\text { orgânicos." (p. 4, grifo nosso). }\end{array}$ \\
\hline
\end{tabular}


O jogo da compreensão na análise textual discursiva em pesquisas ...

Quadro 1. continuação

\begin{tabular}{|c|c|}
\hline Tese & Excerto \\
\hline $\begin{array}{l}\text { DUVOISIN, I. A. Virtualizações e } \\
\text { atualizações em redes de conversação } \\
\text { sobre o currículo de um curso on-line } \\
\text { de licenciatura em ciências. 2013. } 179 \text { f. } \\
\text { Tese (Doutorado em Educação em Ciências) } \\
\text { - Universidade Federal do Rio Grande, Rio } \\
\text { Grande, } 2013 .\end{array}$ & $\begin{array}{l}\text { "Trata-se de uma pesquisa de cunho qualitativo, } \\
\text { cujo objetivo não é a generalização nem a busca de } \\
\text { leis ou princípios, mas a compreensão particular do } \\
\text { que se estuda, ou seja, o foco da atenção desloca- } \\
\text { se da generalização para o específico, o peculiar, o } \\
\text { individual, almejando sempre a compreensão do } \\
\text { fenômeno estudado." (p. 6, grifo nosso). }\end{array}$ \\
\hline $\begin{array}{l}\text { FIRME, M. V. F. Seminário integrado: } \\
\text { as faces do reconhecimento do outro para } \\
\text { professores de ciências participantes do } \\
\text { cirandar. } 2017.132 \text { f. Tese (Doutorado em } \\
\text { Educação em Ciências) - Universidade Federal } \\
\text { do Rio Grande, Rio Grande, } 2017 .\end{array}$ & $\begin{array}{l}\text { "Nesta tese apresentam-se as compreensões sobre } \\
\text { o que se mostrou do Seminário Integrado, uma } \\
\text { componente curricular para articular as áreas de } \\
\text { conhecimento [...]" (p. 8, grifo nosso). }\end{array}$ \\
\hline $\begin{array}{l}\text { FONSECA, T. M. M. V. Processos } \\
\text { educativos emergentes da relação médico- } \\
\text { paciente sobre DST e a autopercepção } \\
\text { de risco entre gestantes. 2014. } 226 \text { f. } \\
\text { Tese (Doutorado em Educação em Ciências) } \\
\text { - Universidade Federal do Rio Grande, Rio } \\
\text { Grande, } 2014 .\end{array}$ & $\begin{array}{l}\text { "Os objetivos norteadores deste estudo } \\
\text { foram: compreender os processos educativos } \\
\text { emergentes da relação médico(a)-paciente sobre } \\
\text { a doença sexualmente transmitida (DST) e a } \\
\text { autopercepção de risco entre gestantes que utilizam } \\
\text { o Sistema Único de Saúde para a realização de } \\
\text { acompanhamento pré-natal.” (p. 6, grifo nosso). }\end{array}$ \\
\hline $\begin{array}{l}\text { HECKLER, V. Experimentação em ciências } \\
\text { na EAD: indagação online com os professores } \\
\text { em AVA. 2014. } 242 \text { f. Tese (Doutorado em } \\
\text { Educação em Ciências) - Universidade Federal } \\
\text { do Rio Grande, Rio Grande, 2014. }\end{array}$ & $\begin{array}{l}\text { "Esta tese de doutoramento apresenta } \\
\text { compreensões sobre como uma comunidade } \\
\text { de professores em pesquisa-formação online } \\
\text { desenvolve/compreende a experimentação em } \\
\text { Ciências na Educação a Distância (EaD)." (p. 8, } \\
\text { grifo nosso). }\end{array}$ \\
\hline $\begin{array}{l}\text { LOUREIRO, L. H. F. Como nos tornamos } \\
\text { formadores na roda da licenciatura para } \\
\text { a educação profissional e tecnológica. } \\
\text { 2013. } 187 \text { f. Tese (Doutorado em Educação } \\
\text { em Ciências) - Universidade Federal do Rio } \\
\text { Grande, Rio Grande, } 2013 \text {. }\end{array}$ & $\begin{array}{l}\text { "Esta pesquisa teve como objetivo compreender } \\
\text { como ocorreu a formação de formadores } \\
\text { enquanto formavam docentes para atuar na } \\
\text { educação profissional de nível médio e na educação } \\
\text { tecnológica de nível superior." (p. 6, grifo nosso). }\end{array}$ \\
\hline $\begin{array}{l}\text { OLIVEIRA, D. Biodiversidade em políticas } \\
\text { públicas de ciência, tecnologia e inovação: } \\
\text { caracterização e perspectivas na integração do } \\
\text { fomento à divulgação e educação em ciências. } \\
\text { 2016. } 230 \text { f. Tese (Doutorado em Educação } \\
\text { em Ciências) - Universidade Federal do Rio } \\
\text { Grande, Rio Grande, } 2016 .\end{array}$ & $\begin{array}{l}\text { "A presente pesquisa investigou editais e } \\
\text { chamadas públicas do Conselho Nacional de } \\
\text { Desenvolvimento Científico e Tecnológico - CNPq } \\
\text { e algumas ações e materiais produzidos, com a } \\
\text { intenção de compreender a integração entre o } \\
\text { fomento à pesquisa e a divulgação científica ou } \\
\text { popularização da ciência, [...]" (p. 10, grifo nosso). }\end{array}$ \\
\hline $\begin{array}{l}\text { SARAÇOL, P. V. A potencialidade do } \\
\text { Proeja: histórias dos estudantes evadidos } \\
\text { do IFRS câmpus Rio Grande. 2014. } 288 \text { f. } \\
\text { Tese (Doutorado em Educação em Ciências) } \\
\text { - Universidade Federal do Rio Grande, Rio } \\
\text { Grande, } 2014 .\end{array}$ & $\begin{array}{l}\text { "A presente investigação situa-se na área da } \\
\text { integração da Educação Profissional com Educação } \\
\text { Básica na Modalidade de Jovens e Adultos } \\
\text { (PROEJA) e busca a compreensão das vivências } \\
\text { dos estudantes do curso no Câmpus Rio Grande } \\
\text { [...]" (p. 6, grifo nosso). }\end{array}$ \\
\hline
\end{tabular}


Quadro 1. continuação

\begin{tabular}{|c|c|}
\hline Tese & Excerto \\
\hline $\begin{array}{l}\text { SILVEIRA, J. F. B. No picadeiro da } \\
\text { educação física: o saber circense } \\
\text { descortinando uma educação crítico- } \\
\text { emancipatória. 2013. } 133 \text { f. Tese (Doutorado } \\
\text { em Educação em Ciências) - Universidade } \\
\text { Federal do Rio Grande, Rio Grande, } 2013 .\end{array}$ & $\begin{array}{l}\text { "Esta pesquisa objetivou compreender como os } \\
\text { saberes circenses podem se constituir, a partir da } \\
\text { práxis docente, em conteúdos potencializadores } \\
\text { de uma educação crítico-emancipatória, [...]" (p. 8, } \\
\text { grifo nosso). }\end{array}$ \\
\hline $\begin{array}{l}\text { SOUSA, R. S. A hermenêutica filosófica } \\
\text { no horizonte da educação química: o } \\
\text { professor de química como tradutor-intérprete } \\
\text { de uma tradição de linguagem. 2016. } 100 \text { f. } \\
\text { Tese (Doutorado em Educação em Ciências) } \\
\text { - Universidade Federal do Rio Grande, Rio } \\
\text { Grande, 2016. }\end{array}$ & $\begin{array}{l}\text { "Sob a influência de Gadamer, buscamos } \\
\text { compreender seu conceito de tradição de } \\
\text { linguagem, a partir do modo como algo é } \\
\text { transmitido a partir de usos e costumes da tradição } \\
\text { escrita, [...]" (p. 8, grifo nosso). }\end{array}$ \\
\hline $\begin{array}{l}\text { VANIEL, B. V. (Co)educar em rede de } \\
\text { conversação: formação de professores } \\
\text { em educação à distância. 2012. } 180 \text { f. Tese } \\
\text { (Doutorado em Educação em Ciências) - } \\
\text { Universidade Federal do Rio Grande, Rio } \\
\text { Grande, } 2012 .\end{array}$ & $\begin{array}{l}\text { "Esta tese visou compreender como nos } \\
\text { formamos professores em EAD ao pensarmos } \\
\text { em um curso de graduação, no operar em redes de } \\
\text { conversação a partir das experiências de quem as } \\
\text { constituem." (p. 8, grifo nosso). }\end{array}$ \\
\hline
\end{tabular}

Fonte: <https://argo.furg.br/>. Acesso em: 21 ago. 2018.

Entendeu-se que os resumos analisados se desdobram na noção de ser a compreensão ato de compreender como atividade de conhecimento específico, distinto do conhecimento racional e de suas técnicas explicativas e mostram a busca por um modo diferente de fazer ciência daquele atribuído às Ciências Naturais em que ainda se percebem dicotomias em relação entre o pesquisador e o objeto a ser "dominado" (ROHDEN, 2002).

Na Filosofia, Gadamer (2015) apresenta como problema da hermenêutica o fenômeno da compreensão e da maneira correta de interpretar o que se entende. Anuncia de antemão que o problema da hermenêutica não pode se restringir ao problema dos métodos das ciências do espírito. A compreensão ocorre como uma fusão do horiz̧onte do texto com o horizonte daquele que o compreende. A compreensão é como uma conversa em que o Ser que pode ser compreendido é linguagem. Assim, Gadamer se propõe a explicar como se justificam os preconceitos no evento da compreensão (SCHMIDT, 2006, p. 140-188). Esta perspectiva de compreensão de textos do mundo por meio da linguagem aproxima a ATD da hermenêutica Gadameriana. (SOUSA; GALIAZZI, 2017b).

\section{No jogo do quebra-cabeças a descrição e teorias a priori como pré-compreensões}

$\mathrm{Na}$ primeira categoria resultante da análise foram reunidos fragmentos dos resumos que indicam os pressupostos teóricos e o modo descritivo de apresentar os resultados. De um 
lado, a descrição tomada no imediato do vivido e constatado fez pensar em uma realidade tomada como se mostrando pelas palavras dos sujeitos investigados. Do outro lado, a realidade expressa pelas palavras da teoria a priori também mostrou uma perspectiva de realidade que se apresenta apenas com as palavras inerentes à própria teoria.

O conjunto de unidades de significados propiciou a construção da seguinte síntese descritiva: percebeu-se, nos resumos, momentos de descrição que apresentavam os resultados da análise como observação do vivido e, assim, o observado é considerado como produto transparente da análise. Também, a teoria a priori percebida na linguagem do pesquisador como conceito estruturador dos dados empiricos se mostrou no nome das categorias. Isso remeteu a uma melhor compreensão das pré-compreensões em Gadamer como desenvolvido a seguir.

\section{A distinção das peças no jogo: a descrição como processo analítico na ATD}

Em um exercício descritivo de busca etimológica da palavra compreender, o vocábulo tem origem latina e foi encontrado em registros escritos de Língua Portuguesa a partir do século XIII (CUNHA, 1982). Compreender apresenta o prefixo com que significa junto, em associação, seguido da palavra prehendere que significa segurar, prender fortemente. A palavra latina comprehendo assumiu este significado de que o que se compreende é o que está dentro do compreendido; é o que consta dentro do que é compreendido, ao mesmo tempo que inclui o sujeito que compreende ao significar que o compreendido é percebido e entendido. Os significados mantiveram a origem de conter em si, na sua natureza, numa categoria ou num sistema e também de apreender algo intelectualmente, usando a capacidade de entendimento, percepção, atino. Também, na cultura, compreender pode significar que a ação foi estendida, ou seja, do compreendido anterior algo foi incluído, incorporado. Também pode significar a concepção de um sujeito sobre determinada coisa. À palavra compreender se agregam significados como o espírito de complacência para com as dificuldades bem como de estabelecer o conjunto de características, qualidades propriedades contidas em um conceito e de comunicar com coerência a mensagem (HOUAISS; VILLAR, 2009). Em termos etimológicos e de acepções dicionarizadas, compreender está para além do domínio de um objeto, que inclui aquele que busca compreensão. É um compreender como ato de conhecer e conhecer-se, de conter em si, constar, abranger, perceber, entender e de significar o espírito de complacência com as dificuldades. Complacência essa como finitude daquele que (se) compreende, inclusive em relação a suas dificuldades e a dos outros envolvidos nesse processo de compreensão.

Em dois resumos analisados (ver Quadro 1), Fonseca (2014) e Silveira (2013), o enfoque descritivo se mostrou na apresentação dos resultados dos processos educativos com a descrição do observado. $\mathrm{Na}$ descrição da relação médico-paciente, apontando para o cuidado com o corpo, para as DST e para a discrepância entre o conhecimento do paciente e do médico:

Os resultados da pesquisa mostram que os profissionais demonstram conhecer o tema e sabem dos riscos para a evolução da gestação. Contudo, os relatos das gestantes se contrapõem a essa afirmativa, quando indicam que esses saberes não são construídos durante a consulta pré-natal. (FONSECA, 2014, p. 6). 
Percebe-se a descrição como resultado final da compreensão também nos resultados da análise da atividade circense, considerada como um conteúdo inovador e promotor de melhor interação entre professor e alunos para escapar da tradição:

Os saberes circenses como conteúdo inovador e a interação professor-aluno foram analisados como categorias finais que emergiram do campo de estudo. Pode-se inferir que os saberes circenses se apresentam como conteúdo inovador e propiciam escapar de uma proposta de Educação Física tradicional. (SILVEIRA, 2013, p. 8).

O que se mostrou nos resumos é a constatação do empírico e do vivencial, ou seja, a interpretação ficou próxima da descrição. O texto ficou no dito para redizer o sabido sobre a discrepância do conhecimento médico e paciente ou para dizer que o conteúdo circense é inovador ou para considerar a ATD como organizadora das categorias.

Isto remete à ideia de um jogo de quebra-cabeça, cuja paisagem já está definida a priori, exigindo do jogador encontrar as peças certas a serem postas em seus devidos lugares. Nem por isso o jogo deixa de ser interessante ao jogador, pois resulta em exercício intelectual de percepção daquele que joga. Assim se constitui o processo de descrição, em que o sujeito que descreve vai se dando conta de como melhor descrever a paisagem acerca do fenômeno em estudo. Para Bicudo (2011, p. 38) "a descrição como a própria palavra diz, descreve, diz do ocorrido, do percebido. Não traz julgamentos interpretativos. Pode ser do investigado, pode ser do pesquisador que descreve o percebido no modo de conforme percebe." No processo de análise com ATD para o estabelecimento de categorias, a descrição é um movimento na linguagem para que o próprio sujeito se dê conta do modo como o fenômeno se mostra, para que perceba suas pré-compreensões e preconceitos, o que pode levar à ampliação ou mesmo à superação deles.

\section{A organização das peças do quebra-cabeça: o movimento de teorias a priori estrutura a pesquisa}

As teorias a priori se fizeram perceber ao longo do corpus de análise quando as hipóteses são apresentadas e expressas pelas palavras que remeteram a teorias específicas, como em Vaniel (2012), Araújo (2017) e Alvarenga (2016):

Nossa hipótese é de que, para o desenvolvimento de uma proposta de formação de professores exista a necessidade da vivência, da discussão e da problematização sobre o fazer docente. Essa discussão, se ocorrer de forma recursiva e recorrente e em uma rede de conversação, permeada pela ausência de fundação e ela aceitação do outro em sua legitimidade torna possível a mudança de padrões habituais de conduta. (VANIEL, 2012, p. 8).

Os lugares e as oportunidades de formação interdisciplinar em Ciências da Natureza, auto-eco-organizam-se na ação ecologizada da prática docente dos sujeitos, por meio de um currículo dialógico disciplinar/interdisciplinar, 
que os desafia ao pensamento transdisciplinar. Dessa forma, ressaltamos o movimento recursivo de formação, entre sujeitos e seus pensamentos, como nesse processo de interação com o objeto que se mostra por intermédio do currículo e na ação realizada pelos estudantes nesse processo de auto-ecoformação. (ARAÚJO, 2017, p. 9).

Por isso, a colaboração, a dialógica e as interações são princípios que potencializam a construção de currículos interdisciplinares e transdisciplinares, bem como a auto-eco-formação permanente dos docentes em seus contextos de atuação. (ALVARENGA, 2016, p. 7).

Os pesquisadores usam palavras como ausência de fundação e aceitação do outro como legítimo, recursão do conversar, enação, (co)educar, convivência, auto-eco-formação, dialógica, próprias da teoria do grupo de pesquisa a que pertencem.

As rodas de formação em Albuquerque (2012), a estética, o escrever e as rodas de formação em Freitas (2015) são teorias a priori assumidas pelo grupo de pesquisa das quais fazem parte:

Alguns pressupostos orientaram a pesquisa: a formação acadêmico-profissional de sujeitos pesquisadores da sua prática em Rodas de Formação, a partir da qual, é possível o acolhimento de questionamentos, a partilha, a escuta, a construção e divulgação de novos argumentos; a escrita como modo de pensar, que por ser uma atividade interativa conta com a presença de interlocutores ativos para provocar o escrevente. (ALBUQUERQUE, 2012, p. 5).

Também Loureiro (2013) parte do empírico e assume as categorias teóricas do grupo de pesquisa na apresentação do argumento da tese.

Como, simultaneamente, atuávamos em um curso que formava professores, a nossa formação ocorreu com a perspectiva de formar-se ao formar. Para alcançar este objetivo, tacitamente, nos organizamos sob a forma de uma Comunidade Aprendente. Nos encontros presenciais as atividades foram realizadas em Roda (Warschauer, 2001), ou seja, na Roda dos Formadores. (LOUREIRO, 2013, p. 6).

Outro modo de expressão das teorias a priori está no anúncio do conceito estruturador da pesquisa - os intelectuais orgânicos de Gramsci na pesquisa de Crivellaro (2013), cujo conceito se relaciona com as características empíricas do fenômeno durante a análise. "Para Gramsci o intelectual é mais do que uma pessoa das letras, ou um produtor e transmissor de ideias. Os intelectuais são também mediadores, legitimadores, e produtores de práticas sociais; eles cumprem uma função de natureza eminentemente política”. (CRIVELLARO, 2013, p. 4).

A ATD tem a descrição como parte estruturante do processo em que até aqui novamente nos remete ao modo de jogar de um quebra-cabeças, cuja paisagem que se busca descobrir já 
está, de certo modo, pressuposta. A ATD não desconsidera esta pressuposição. Pelo contrário, parte delas em busca de ampliar compreensões do fenômeno em análise. A ATD exige teoria, não obstante, a teoria que ela demanda (a priori ou emergente) precisa se mostrar em movimento epistêmico do próprio pesquisador. Nesta metodologia de análise, o fundamental é ir além do sabido. Isso nos levou a compreender que as unidades de significado desta categoria se mostraram mais como pré-compreensões do que como horizontes abertos.

\section{No jogo da produção de um mosaico: o movimento para compreensão}

$\mathrm{Na}$ segunda categoria resultante da análise, percebeu-se o movimento de como fazer pesquisa e em que teorias as teses se estruturaram. Isto permitiu escrever a síntese descritiva: percebeu-se, nos resumos, um movimento de mudança da compreensão inicial da pesquisa nos procedimentos da metodologia em que o pesquisador faz modificações de acordo com seu material empírico e no encontro com teorias desconhecidas antes da pesquisa ou teorias assumidas a priori, mas que foram ampliadas no decorrer da pesquisa. Esta categoria abrangeu movimentos: nas epistemologias, nas teorias a priori e na emergência de teorias, como se mostra a seguir.

\section{Diferentes paisagens possíveis no mosaico:}

\section{a ATD como metodologia em diferentes epistemologias}

O modo como um pesquisador percebe e entende a realidade articula-se com os procedimentos analíticos inerentes à pesquisa. Nem todos os resumos explicitaram a epistemologia assumida, mas os que o fizeram possibilitaram escrever a síntese descritiva que segue: a ATD foi utilizada com os autores das pesquisas analisadas, assumindo nos resumos a abordagem dialético materialista em Freitas (2015), a hermenêutica filosófica em Saraçol (2014), Heckler (2014) e Sousa (2016), a particularidade da pesquisa sem intenção de generalização colocando a verdade entre parênteses em Duvoisin (2013), a complexidade em Araújo (2017). Percebeuse, pelos resumos, a pertença a um modo de produzir ciência também pelos procedimentos relatados em que a recursividade e a trama conceitual, como procedimentos produtores de compreensões foram assumidos, como os exemplos a seguir:

A partir da abordagem dialético-materialista foi feita análise dos registros produzidos de março de 2011 a março de 2013, pela metodologia Análise Textual Discursiva. As informações foram produzidas em práticas educativas desenvolvidas em cinco componentes curriculares, dois projetos de ensino e dois projetos de extensão. (FREITAS, 2015, p. 11).

Esta é uma pesquisa-ação prático-colaborativa com base filosófica fenomenológica hermenêutica, desenvolvida pela produção textual auto-organizada de metatexto, em que o corpus de análise das informações teóricas e empíricas é estudado por meio da Análise Textual Discursiva (ATD), incluindo as três categorias emergentes na construção dos argumentos centrais do estudo. (HECKLER, 2014, p. 9). 
A partir das perspectivas epistemológicas e hermenêuticas presentes nas teses, concordamos com Ginev (1995) que considera epistemologia como a posição filosófica que objetiva revelar as condições transcendentais (aquilo que é conhecido como condição a priori e não a partir da experiência) das construções epistêmicas elaboradas dentro de diferentes tipos de ciência. Neste caso, o questionamento epistemológico desfecha em um modo não prescritivo de condições internas de auto-organização cognitiva do conhecimento científico.

Por outro lado, a hermenêutica, Ginev denomina de posição filosófica que questiona as diferentes pré-estruturas do conhecimento científico em que a principal tarefa não é revelar a estrutura do conhecimento conceitualmente articulado, mas estudar o processo de articulação conceitual dentro da primordial "fusão de horizontes" (GINEV, 1995, p. 149). Portanto, a investigação hermenêutica lida com as transformações do mundo-trabalho e a gênese das atitudes teóricas em relação ao mundo, enquanto a tarefa da epistemologia é revelar as auto-organizações cognitivas dos modos existenciais guiados por projetos tematizados do "mundo". Sobre a pesquisa científica, Ginev (1995, p. 158) conclui que se deve levar em conta que se está em um jogo entre as dimensões epistemológicas e hermenêuticas no processo de formação de discursos científicos, pois, no diálogo entre essas dimensões estão colocadas tanto uma compreensão filosófica de ciência, quanto a estrutura interna da própria ciência. Percebeu-se, portanto, um movimento de jogo das teses entre essas dimensões, em que não se considera nas pesquisas apenas o "mundo" tematizante com teorias a priori, nem apenas uma projeção do "mundo" interpretado hermeneuticamente.

\section{A ideia do mosaico: a emergência é movimento para a compreensão}

No capítulo 3 do livro de ATD (MORAES; GALIAZZI, 2007), os autores questionaram se os processos de análise na ATD, especialmente a categorização, seriam de construção de quebra-cabeças ou de mosaicos. Até agora, viu-se que o processo analítico agarrado às teorias a priori do pesquisador ou do grupo de que pesquisa que se insere remeteram mais à ideia de quebra-cabeça, Entretanto, na ATD podem ser assumidas teorias emergentes. O sentido dado à palavra emergência é aquele da compreensão que surge durante o processo de análise, que o pesquisador como sujeito histórico percebe, o que o leva a uma teoria antes não reconhecida, mas parte de suas pré-compreensões. Este movimento de emergência de compreensão se aproxima da ideia círculo hermenêtico que Weiss $(2005$, p. 6) interpreta como espiral hermenêutica, que:

De leituras reiteradas do texto se transformam as antecipações e as interpretações. Aprofunda-se a compreensão ao relacionar determinadas partes ou significados do texto (palavras, conceitos, metáforas, motivos) com outros textos e vislumbrar o diálogo explícito e implícito que se estabelece entre estes textos. Também se aprofunda na medida em que surgem possibilidades diversas de relacionar determinadas partes (e/ou significados) do texto com outras partes do mesmo. Usualmente surgem primeiras análises parciais relacionadas com elementos ou temas do texto, assim como intuições isoladas sobre as relações de significados latentes. As interpretações parciais sucessivas se submetem à prova da releitura, e dela e da reflexão sobre as relações entre análises e interpretações parciais 
só pode surgir uma configuração de sentido, que se pode considerar como uma nova interpretação interessante.

A emergência se mostra nos resumos analisados: nas categorias que permitiram ao pesquisador se apropriar de teoria antes desconhecida do grupo de pesquisa ou do pesquisador como a narrativa como produtora de currículo em Albuquerque (2012); as comunidades aprendentes em Loureiro (2013); a epistemologia da prática em Cacciamani (2012); a hermenêutica filosófica em Saraçol (2014) e Sousa (2016); a experimentação online em Heckler (2014) e o reconhecimento do outro em Firme (2016). Também se mostra a emergência no âmbito da teoria assumida a priori pela pesquisadora (teoria do grupo de pesquisa), mas que se especifica na teorização do fenômeno situado do Fluzz currículo em Duvoisin (2013). Outra emergência se apresenta nas categorias empíricas, como a fragmentação do conhecimento e isolamento das áreas e o distanciamento das instituições formadoras que levou Duvoisin (2013) a utilizar palavras diferentes das teorias a priori. O que emerge, também, nos resultados de Saraçol (2014) é como a contradição da evasão pode engendrar possibilidades de transformação e em Sousa (2016) percebendo possibilidades para a Educação Química, como mostrado a seguir:

Como conclusões a pesquisa aponta para a inadequação do curso em seus diversos aspectos. Reforça que a construção curricular adaptada de um curso existente foi um equívoco. A formação dos professores e gestores promoveu a proposta de um curso repleto de contradições. Mesmo com todos os distanciamentos, o curso promoveu um ensino de qualidade na formação humana e por isso os estudantes desenvolveram sentimentos positivos quanto ao curso. Promoveu os estudantes a novas oportunidades na sua vida social, inclusive com ingresso na universidade. A tese geral aponta para a potencialidade do PROEJA do Câmpus Rio Grande, na transformação da realidade do sujeito, apesar do alto índice de evasão e da inadequação do curso. (SARAÇOL, 2014, p. 7).

Entre os desdobramentos que emergem dessa discussão, destacamos a reivindicação do diálogo, da tradição histórica e da escrita na Educação Química, como outros modos interpretativos da linguagem da Química. Com esta investigação, defendemos a abertura filosófico-educativa da Educação Química à hermenêutica filosófica, dentro da qual é possível interpretarmos linguisticamente sobre o diálogo e sobre a tradição histórica da linguagem da Química. (SOUSA, 2016, p. 8).

Estas emergências mostradas nos resumos das teses podem ser associadas a ajustes às peças do quebra-cabeça do fenômeno em investigação. São feitos ajustes às peças que o compõe. Suas formas originais não foram suficientes para possibilitar formação da paisagem exigida pelo fenômeno. O pesquisador modificou as formas das peças, formando não mais um quebra-cabeças, mas um mosaico mais coerente com a imagem do fenômeno em estudo. 


\section{A paisagem do mosaico diferente do planejado: o movimento para a teoria ampliada}

O movimento de análise na ATD, seja a partir de teorias a priori, do grupo de pesquisa, seja de categorias empíricas emergentes, pode levar a compreensões ampliadas. Como se mostraram nos resumos a seguir. A articulação de diferentes distintas teorias, no argumento de Freitas (2015, p. 11), mostra esta ampliação teórica possibilitada pela análise:

Defendo como tese que assumir a formação de professores(as) de Ciências da Natureza como formação acadêmico-profissional e valorizar o fundamento estético neste processo favorece transformações nos(as) envolvidos(as), no sentido de desenvolver a consciência crítica sobre o papel do(a) professor(a) e o exercício de aprender a estar em comunidade.

A ampliação da compreensão da teoria a priori se mostra no resumo também no encontro de um conceito próprio para a pesquisa:

Foi o processo recursivo de análise e síntese da ATD e a visualização da trama das redes de conversações no NVivo que nos fizeram perceber que o currículo é para além de uma categoria: é a própria atualização que emerge como solução inventiva às problemáticas nessas redes e, por isso, denominamos Fluzz Currículo. (DUVOISIN, 2013, p. 75).

O expresso sobre fenômeno situado da experimentação online mostra também a ampliação da compreensão em Heckler (2014), como está posto em Bicudo (2011, p. 55): “A pesquisa do fenômeno situado se dedica ao estudo disso que se mostra quando perguntamos pelo o que é isso que se mostra? Mas aquilo que se mostra, não se mostra, nem poderia, conforme a concepção fenomenológica [...], mas se revela na experiência vivida...”.

Mas o que é isso que se mostra neste movimento em direção a compreender melhor a compreensão? Seria essa a fusão interpretativa de horizontes de textos? E o que é horizonte?

Horizonte é uma palavra antiga na língua escrita portuguesa. Surge no século XV e tem significados variados. Como linha circular em que a terra e o mar parecem unir-se ao céu e que limita o campo visual de uma pessoa, o campo de visibilidade, o pano de fundo que aparece num quadro. Também pode significar a dimensão do futuro de alguém ou a perspectiva como representação dos limites do campo do pensamento, da consciência ou de uma atividade (HOUAISS; VILLAR, 2009). Na Filosofia, este termo surgiu com Anaximandro (séc. VI a. C.) que considerou como Princípio como aquilo que abarca todas as coisas e as dirige. Kant entendeu horizonte como o limite e distinguiu horizonte lógico, estético e prático. Husserl entendeu horizonte como limite temporal em que estão todas as vivências. Jaspers desenvolveu a ideia de um horizonte circunscrito, mas que sempre pode ser alargado. Qualquer corrente filosófica pode utilizar para designar os limites de validade de determinada investigação ou o tipo de validade a que aspiram os instrumentos utilizados (ABBAGNANO, 1999).

Ao se colocar a palavra horizonte para compreender mais a compreensão, assume-se a compreensão de que compreender é um evento efetuado historicamente e que as palavras 
são pano de fundo e a base a partir da qual se compreende (SCHMIDT, 2006). Gadamer (2015) entende que a atividade interpretativa se inicia sempre com conceitos prévios que serão substituídos por outros mais adequados. Assim, os preconceitos vão sendo paulatinamente afastados, dando lugar a conceitos mais adequados, em que os sentidos vão ser confirmados, se compatíveis com o texto; e afastados, se forem insuficientes.

O termo horizonte é o conjunto herdado de preconceitos. Aquilo além do que não é possível ver, mas que pode mudar, expandir-se, reduzir-se. Um horizonte nunca é fechado e estático, assim, ao ler um texto o leitor projeta o horizonte do texto dentro de seu próprio horizonte e a compreensão é esta fusão de horizontes que supostamente existem por si mesmos (GADAMER, 2015). De acordo com Schmidt (2006), para Schleiermacher o conhecimento está sempre no círculo hermenêutico, onde cada particular só pode ser compreendido através do geral do qual faz parte e vice-versa. Para compreender uma sentença completa se precisa compreender as partes, mas não se pode compreender as partes sem que se tenha compreendido a sentença completa. Gadamer (2015) não diferencia a interpretação da compreensão, pois, para ele, compreender é sempre interpretar. Assim, o novo conceito faz parte da existência humana. A possibilidade da vida dá-se na medida em que o homem compreende.

Como movimento de compreensão possibilitado pela ATD nos resumos de teses analisados, mostrou-se uma ampliação das compreensões iniciais dos pesquisadores com o encontro de teorias antes distantes de seus horizontes interpretativos. Esta fusão de horizontes nas investigações com ATD mostrou um estar-entre dimensões epistemológica (nem sempre assumida) e hermenêutica, mas que possibilitaram emergências e ampliações teóricas. Nas emergências, teve-se o (re)conhecimento e apropriação de teorias antes não-reconhecidas e que foram por eles expressas linguisticamente. As ampliações teóricas emergem nos caminhos investigativos, em que as categorias epistemológicas iniciais não são suficientes para compreender o fenômeno que se propõe a estudar, principalmente porque este fenômeno carrega consigo características próprias que o investigador não consegue negar e que, neste movimento de compreensão/ interpretação, tornam-se parte linguisticamente da compreensão do mundo do pesquisador. Tem-se, portanto, um movimento que parte de quebra-cabeças cujas peças são modificadas de modo a comporem um mosaico que melhor expressa o fenômeno analisado. Os pesquisadores vão se dando conta de que mesmo com os espaços não totalmente ajustados das peças que compõem este mosaico, mais próximo estará da compreensão do fenômeno.

Ao se buscar resposta à pergunta de que dá título ao capítulo 3 do livro de ATD (MORAES; GALIAZZI, 2007) “Construindo Quebra-Cabeças ou Criando Mosaicos?”, os autores consideram que ambos são possíveis com a ATD. Entretanto, como já dito, o que importa com a ATD é ir além do já sabido, ampliando a compreensão, ou seja, mais próximo da construção de mosaicos compreensivos.

\section{Considerações finais}

Neste estudo, compreendeu-se mais acerca do uso da metodologia de ATD, que consiste no encontro com o fenômeno a ser investigado, que não se mostra de imediato, mas que se elucida com o movimento da análise. Entendeu-se que a análise com a ATD possibilita colocar-se em um jogo entre as perspectivas epistemológicas que se carrega, as teorias a priori 
O jogo da compreensão na análise textual discursiva em pesquisas ...

e as emergências teóricas possibilitadas pelo movimento interpretativo hermenêutico. Nesse caminho, o exercício feito a partir dos significados das palavras intencionalmente escolhidas, permite movimentar-se baseado em preconceitos com vistas a horizontes de compreensão que podem ser ampliados. Nesse processo analítico, pensando no diálogo sobre ATD, é que existe a possibilidade de intensidade, de atentar para a importância da descrição fenomenológica em um movimento de escuta ao que se mostra na interlocução empírica para o exercício hermenêutico de atenção às palavras do pesquisador, para que as pré-compreensões se estendam a compreensões ampliadas.

\section{Referências}

ABBAGnANO, N. Dicionário de filosofia. São Paulo: Martins Fontes, 2007.

ARIZA, L. G. et al. Relaciones entre el análisis textual discursivo y el software Atlas.Ti en interacciones dialógicas. Campo Abierto: revista de educación, Badajoz, v. 34, n. 2 , p. 105-124, 2016.

BERTICELLI, I. A. Epistemologia e educação: da complexidade, auto-organização e caos. Chapecó: Argos, 2006.

BICUDO, M. A. V. Pesquisa qualitativa segundo a visão fenomenológica. São Paulo: Cortez, 2011.

CUNHA, A. G. Dicionário etimológico Nova Fronteira da língua portuguesa. Rio de Janeiro: Nova Fronteira, 1982.

FREITAS, D. P. S. A prática de pensar a prática de formação acadêmico-profissional de professoras(es) de ciências da natureza: estética do formar-se ao formar. 2015. 150 f. Tese (Doutorado em Educação em Ciências) - Instituto de Educação, Universidade Federal do Rio Grande, Rio Grande, 2015.

GADAMER, H. G. Verdade e método I: traços fundamentais de uma hermenêutica filosófica. Petrópolis: Vozes, 2015.

GINEV, D. Between epistemology and hermeneutics. Science \& Education, Dordrecht, v. 4, n. 2, 147-159, 1995.

HOUAISS, A.; VILLAR, M. S. Dicionário Houaiss da língua portuguesa. Rio de Janeiro: Objetiva, 2009.

MORAES, R. A educação de professores de ciências: uma investigação da trajetória de profissionalização de bons professores. 1991. Tese (Doutorado em Educação) Universidade Federal do Rio Grande do Sul, Porto Alegre, 1991.

MORAES, R. Uma tempestade de luz: a compreensão possibilitada pela análise textual discursiva. Ciência \& Educação, Bauru, v. 9, n. 2, p. 191-211, 2003. Disponível em: <http://dx.doi.org/10.1590/S1516-73132003000200004>. Acesso em: 20 ago. 2018. 
MORAES, R.; GALIAZZI, M. C. Análise textual discursiva. Ijuí: Editora Unijuí, 2007.

MORAES, R.; GALLIAZI, M. C. Análise textual discursiva: processo reconstrutivo de múltiplas faces. Ciência \& Educação, Bauru, v. 12, n. 1, p. 117-128, 2006. Disponível em: <http://dx.doi.org/10.1590/S1516-73132006000100009>. Acesso em: 21 ago. 2018.

ROHDEN, L. Hermenêutica filosófica. São Leopoldo: Unisinos, 2002.

SCHMIDT, L. K. Hermenêutica. Petrópolis: Vozes, 2006.

SOUSA, R. S.; GALIAZZI, M. C. A categoria na análise textual discursiva: sobre método e sistema em direção à abertura interpretativa. Revista Pesquisa Qualitativa, São Paulo, v. 5, n. 9, p. 514-538, $2017 \mathrm{a}$.

SOUSA, R. S.; GALIAZZI, M. C. Compreensões acerca da hermenêutica na análise textual discursiva: marcas teórico-metodológicas à investigação. Revista Contexto \& Educação, Ijuí, v. 31, n. 100, p. 33-55, 2017b.

WEISS, E. Hermenéutica crítica, uma reflexión metodológica, sociológica y epistemológica.

Paideia: revista de la UPN, León, v. 1, n. 1, p. 7-15, jul-dec. 2005.

Artigo recebido em 21/07/2016. Aceito em 04/03/2018.

Contato: Universidade Federal do Triângulo Mineiro, Campus Universitário de Iturama, Avenida Rio Paranaíba, 1229, Centro, Iturama, MG, 38280-000, Brasil. 